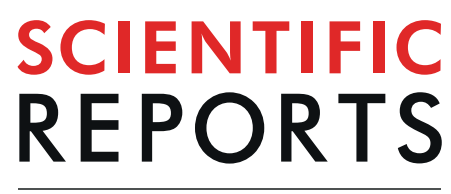

\title{
Differences in vegetative growth of two invasive hawkweeds at temperatures simulating invaded habitats at two altitudes
}

\begin{abstract}
Kris French $\mathbb{D}^{*} \&$ Eva Watts
Hieracium pilosella and $H$. aurantiacum are invading alpine regions in New South Wales, Australia. In a glasshouse experiment we investigated germination and growth rates of these two species at temperatures simulating the altitudes where invasions are occurring from autumn to spring. We measured germination rates, growth rates and the development of stolons and ramets using seedlings and plantlets from established plants. Germination was low in $H$. aurantiacum and unaffected by altitude or seed age. $H$. pilosella showed site to site variability in germination but had greater germination. No species produced flower spikes. Both species grew rapidly and put at least twice as much biomass into roots compared to shoots. H. aurantiacum could begin to produce stolons after 27 days and seedlings grew a little larger than for $H$. pilosella. Hieracium aurantiacum put significantly more resources into ramets, allocating between $4-15 \%$ of biomass. $H$. pilosella produced 2.6 stolons month ${ }^{-1}$, in contrast to 9.8 stolons month ${ }^{-1}$ for $H$. aurantiacum. Furthermore, plantlets from established plants had vastly different growth rates. Plantlets of $H$. aurantiacum produced 2.1 leaves day $^{-1}$ from late summer to winter where $H$. pilosella was 3 times slower for the same period but faster following winter. Both species were able to maintain strong growth over cooler months suggesting hawkweeds have the capacity for fast growth in the invaded range under high nutrients and lower competition. $H$. aurantiacum is likely to be a more effective invader than $H$. pilosella spreading through stolons and the development of weed mats.
\end{abstract}

Hawkweeds (Hieracium spp. Asteraceae) are native to subalpine regions in Central Europe but form significant invasions in grasslands in USA ${ }^{1}$, Argentina and Chile ${ }^{2,3}$ and New Zealand ${ }^{4,5}$. Three species have invaded Australia, but at present, in the alpine regions of NSW, two of the species are in early stages of establishment; orange hawkweed (Hieracium aurantiacum L.) and mouse-ear hawkweed (Hieracium pilosella L.) ${ }^{6}$.

Both species are undergoing an eradication program in New South Wales, Australia, however, three aspects are of concern for the establishment of these invasive daisies if eradication fails. Firstly, both species are important weeds in other grasslands and, while global changes in climate might reduce overall distribution, there is no reason why they will not become widely established in the NSW alps and invade lower altitudes ${ }^{7,8}$. Secondly $H$. aurantiacum and $H$. pilosella can be apomictic ${ }^{9-11}$ and can therefore spread quickly with the establishment of single plants. Thirdly, both species are matt-forming, producing many stolons with ramets which allow genets to quickly take over available space in the landscape. Clonal plants are thought to improve resource capture as nutrients are redistributed between ramets and mother plants ${ }^{12,13}$. Clonal growth has been shown to play an important role in the spread of invasive species ${ }^{14,15}$. For example, populations of Solidago gigantea in the invaded range used clonal growth more than in the native range $\mathrm{e}^{16,17}$. So, the speed at which hawkweed genets grow is an important factor in determining the priorities for management to prevent spread. Understanding differences in growth associated with temperature will yield information on growth at different altitudes. Furthermore, while $H$. pilosella

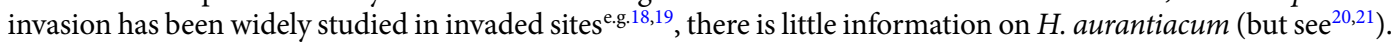

The speed of germination, growth of individual plants and production of stolons and ramets all form important aspects in establishment, particularly for species that rely so heavily on clonal reproduction. For the climates in which these two species have invaded in the NSW alps, we sought to compare the rate of growth, of both 
seedlings and plantlets to understand potential establishment rates. Furthermore, we sought some understanding of germination rates from different populations grown at temperatures reflective of establishment sites.

\section{Methods}

Germination and growth trials were undertaken from January - October 2018. Experiments were undertaken in incubators and growth cabinets which could be maintained at temperatures reflective of the altitudes that these species currently experience in Australia. Incubators were able to maintain low temperatures experienced in winter and had a PAR of $21 \mu \mathrm{mol} \mathrm{m} \mathrm{m}^{-2} \mathrm{~s}^{-1}$ which is similar to that experienced under snow. Growth cabinets had a PAR of $485 \mu \mathrm{mol} \mathrm{m}{ }^{-2} \mathrm{~s}^{-1}$ which equated to that experienced on a cloudy day $\left(510 \mu \mathrm{mol} \mathrm{m} \mathrm{m}^{-2} \mathrm{~s}^{-1}\right)$.

Temperatures were set each month using average weather station data from around $1000 \mathrm{~m}$ (Hill Prison Camp $1006 \mathrm{~m}$ ) or $1700 \mathrm{~m}$ asl (Perisher Valley AWS $1738 \mathrm{~m}$ ) for each month. To calculate a typical day time temperature for any month, we identified the maximum temperature for each day within a month then took the midpoint between the highest and lowest temperature. We followed the same method to identify the night time temperature using minimum temperatures for each night of a month. Day and night length throughout all experiments reflected, and were adjusted to, the months we simulated.

Germination. Germination of H. aurantiacum used seeds from three sites collected over the 2017/2018 summer (termed New) and older seeds from four sites (termed Old) that had been stored in paper bags at room temperature for up to four years. For each site, eight replicates of each of three temperature treatments were set up; temperatures replicating $1000 \mathrm{~m}, 1700 \mathrm{~m}$, and $200 \mathrm{~m}$ asl. Each replicate consisted of 25 seeds placed in a petri dish with filter paper moistened with distilled water. In all, there were 144 petri dishes containing 3600 seeds of H. aurantiacum. Petri dishes in temperatures mimicking alpine temperatures were placed in incubators, while the H. aurantiacum trial at $200 \mathrm{~m}$ was placed in the glasshouse.

Due to the eradication program and resultant scarcity of $H$. pilosella only one site with new seeds collected over the recent summer and three sites with old seed collected in the last 5 years were available. These sites are within metres as there is only one invasion area near Charlotte Pass. As seed numbers were low we could only measure germination at temperatures mimicking $1700 \mathrm{~m}$. The new seed site had only enough seeds for 7 petri dishes while the other sites had 8 petri dishes each. Thus, the $H$. pilosella seed trial contained 31 petri dishes and 775 seeds.

Petri dishes were checked for germination every two weeks and the experiment was terminated on $10^{\text {th }}$ July after just over 15 weeks. Tetrazolium testing of viability of the remainder of seeds in the petri dishes was attempted but without success as the hawkweed seeds are extremely small and seeds did not show any stain even when attempted on new seed material.

We use the term seedlings to be small plants grown from seed in this experiment. To avoid confusion in this study, we use the term 'ramet' as any attached plantlet that has grown on a stolon from its parent seedling or plantlet (See Growth of Seedlings below), while ramets that have been separated from stolons and are independent are identified as 'plantlets' (see Growth of Plantlets below).

Growth of seedlings. As seeds germinated they were planted under the same conditions under which they were germinated, in a seedling plug before being transferred to small pots containing a mixture of general potting mix and coarse river sand (2:1). At the beginning of the seedling growth trial, $40 \mathrm{H}$. aurantiacum seedlings at the three-leaf-stage were potted up from seedling plug trays into small pots ( $130 \mathrm{~mm}$ diameter). From the $1000 \mathrm{~m}$ germination trial, 20 were transferred into a growth cabinet set to $1000 \mathrm{~m}$ conditions and another 20 from the $1700 \mathrm{~m}$ germination trial were transferred into a growth cabinet set to temperatures at $1700 \mathrm{~m}$ (April temperatures). Twenty $H$. pilosella seedlings were also transferred to the cabinet set at temperatures reflecting those at $1700 \mathrm{~m}$ altitude. The seedlings were watered twice a week and fertilized once a month with Osmocote Plus Organics all purpose liquid fertilizer (N: 15.4\%, P: 0.0\%, K: 6.0\%). Plants were moved back into the incubators in June in order to experience winter temperatures.

After 188-189 days, plants were harvested. Stolons and leaves were separated from root, and new ramets were counted and separated. All plant parts were dried at $70^{\circ} \mathrm{C}$ for 10 days and then weighed to give dry biomass.

Growth of plantlets. Two large pots of $H$. aurantiacum and one of $H$. pilosella were provided by the Department of Primary Industry. These pots contained multiple plants each with large numbers of stolons with numerous ramets attached. $H$. pilosella plants were at least 3 years old and grown from vegetative stock so three years represents a minimum age. $H$. aurantiacum pots were probably around two years old. Between $27^{\text {th }}$ February and $1^{\text {st }}$ March, ramets were separated and potted up into $130 \mathrm{~mm}$ diameter pots. In all, $45 \mathrm{H}$. aurantiacum and $33 \mathrm{H}$. pilosella ramets were separated into mother plant (those that had stolons emanating from them) and ramets (those who were found at the end of stolons emanating from a mother plant) (Fig. 1). Only ramets of at least 4 to 5 leaves were used; the rest discarded. Initially for $H$. pilosella there were 4 mother plants with an average of $4.75 \pm 1.50$ (s.d) stolons. There were 5 H. aurantiacum mothers with an average of $5.83 \pm 9.02$ (s.d) stolons. Only two of the mother plants from $H$. pilosella and one from $H$. aurantiacum grew and had leaves.

With these established plantlets, there was only room to grow each species under one altitude that best reflected its invasion conditions. Initially, H. aurantiacum plantlets were placed into a Thermoline growth cabinet set to temperatures reflective of $1000 \mathrm{~m}$ asl. $\mathrm{H}$. pilosella plantlets were placed into a separate Thermoline growth cabinet set to temperatures reflective of $1700 \mathrm{~m}$ asl. At the beginning of winter due to limited space, we placed a random set of 12 pots of each species into incubators after repotting in $30 \mathrm{~cm}$ pots, to ensure winter temperatures were maintained and harvested all other plants (day 69 for H. aurantiacum and day 126 for H. pilosella, Fig. 1). Harvested plantlets were separated into above and below ground biomass, and individual ramets before drying and weighing. 


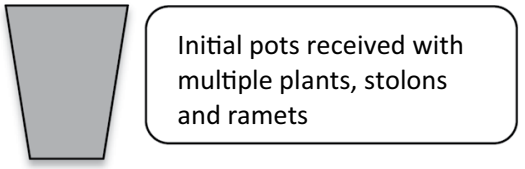

Plants separated into mother plants (those that had stolons) and individual ramets from each mother plant, measured and planted into separate pots

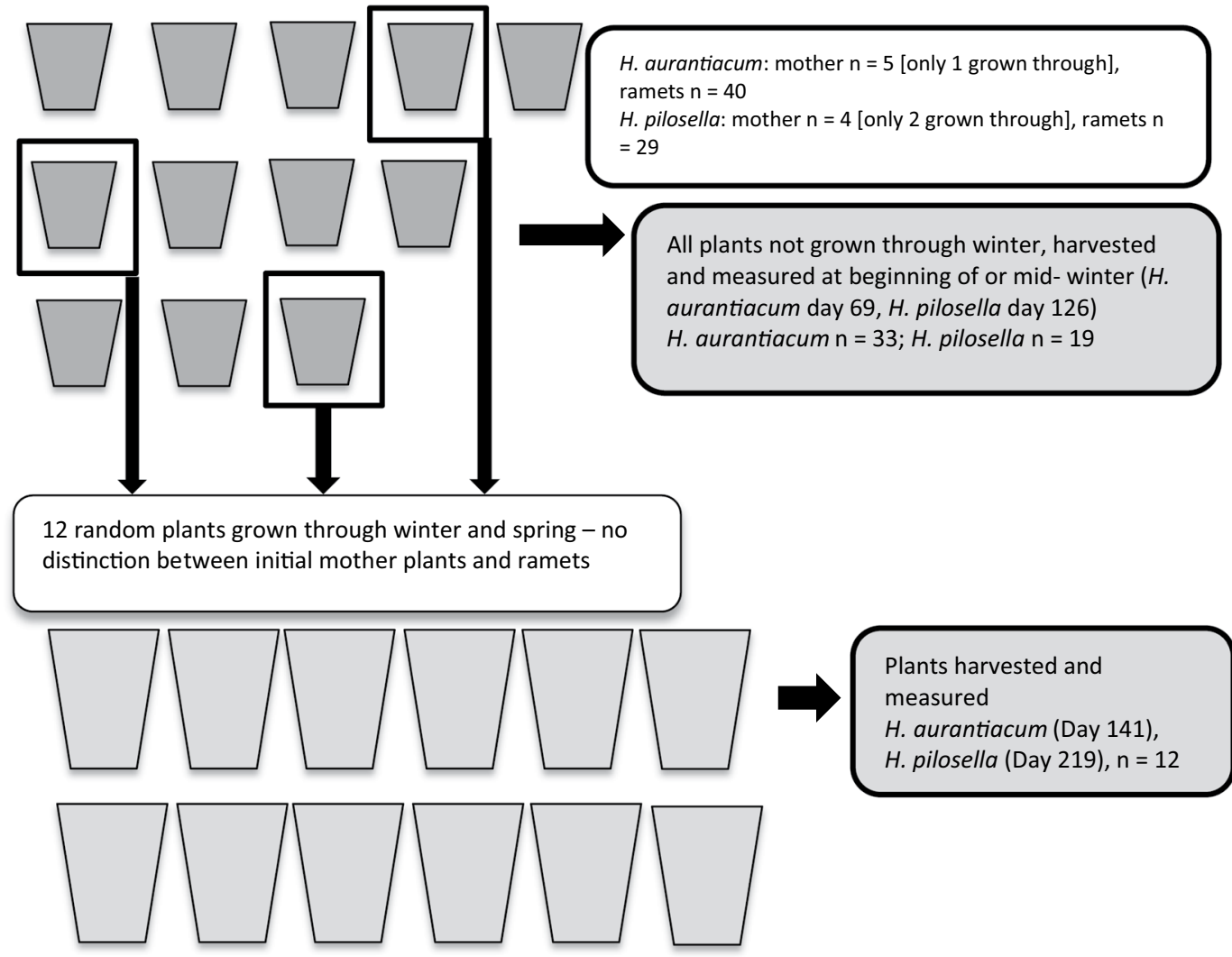

Figure 1. Experimental design for measuring growth of adult plants.

On day $148\left(26^{\text {th }}\right.$ July 2018$) H$. aurantiacum plantlets were harvested as the 12 big plants had completely filled the pots. We continued to monitor for one week past our decision as they experienced some very high temperatures for 2 days at the end of our sampling when the cabinets failed to maintain set temperatures. Daytime temperatures reached $38-40{ }^{\circ} \mathrm{C}$ for a few hours on these days. Rather than harvest immediately, we harvested after a week (day 148) to observe any deaths following this event. Above and below ground dried biomass and individual ramet dry weight were recorded. The remaining $12 \mathrm{H}$. pilosella plantlets also received warmer than planned heating during July as well, but only increased to $24^{\circ} \mathrm{C}$ which was not considered extreme for a warm day at this altitude. They were harvested on day 219 (9-11 October 2018) and above and below ground biomass as well as individual ramets were dried and dry weight recorded.

Analysis. For $H$. aurantiacum the proportion of seeds germinated per petri dish was compared using a restricted maximum likelihood model with age and altitude as fixed factors and site nested within age. For $H$. pilosella, sites were compared as a fixed factor using a standard least squares model as there were no replicate sites nested within age and a lack of seeds meant we could only compare sites at the $1700 \mathrm{~m}$ altitude.

We compared the number of leaves, number of stolons and dry biomass measurements [above ground biomass, below ground biomass, total biomass, proportional mass in ramets and the root:shoot ratio] using mixed models with a binomial distribution and log link function. Stolon weight and leaves were included as above ground biomass while total weight included leaves, stolons, ramets and roots. Where significant effects were found, Tukeys HSD tests were used to identify where differences lay. 


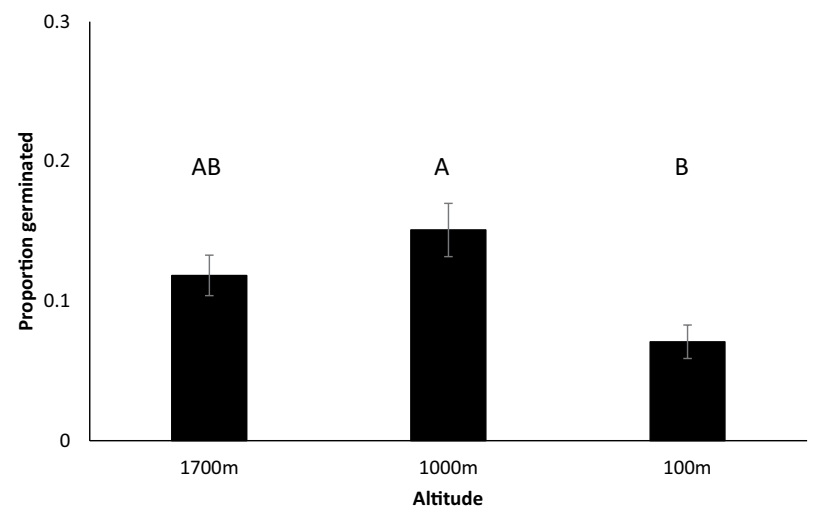

Figure 2. Proportion of $H$. auranticum seeds germinated in petri dishes at conditions representative of three different altitudes. Means based on $\mathrm{n}=48$.

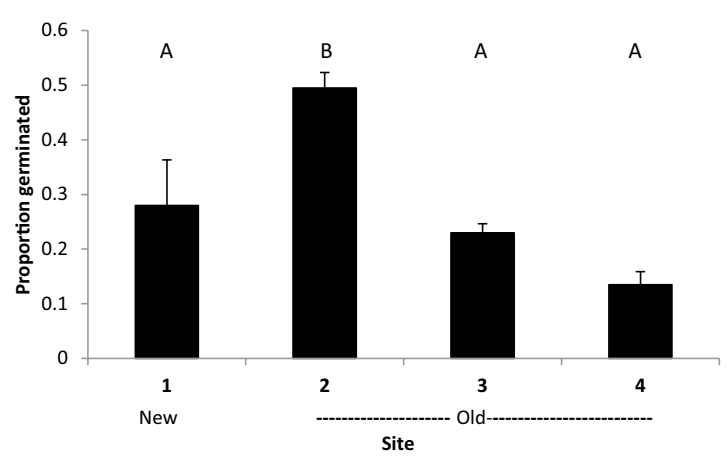

Figure 3. Proportion of $H$. pilosella seeds germinated in petri dishes from four sites at Mt. Koscuizsko. New seeds were fresh from the recent season's reproduction while older seeds had been picked from earlier seasons. Means based on $\mathrm{n}=48$.

\section{Results}

Germination. For H. aurantiacum, a greater proportion of seeds germinated at temperatures mimicking $1000 \mathrm{~m}$ than at $200 \mathrm{~m}$ with $1700 \mathrm{~m}$ being intermediate $\left(\mathrm{F}_{2,9.30}=5.414, P=0.028\right.$, Fig. 2$)$. There was no difference in germination rate between old and new seeds $\left(\mathrm{F}_{1,4.914}=0.571, P=0.485\right)$ nor an interaction between the two main effects $\left(\mathrm{F}_{1,9.30}=0.771, P=0.490\right)$. Sites were highly variable with the proportion germinating ranging from $0.04 \pm 0.01$ to $0.31 \pm 0.04$ suggesting significant site to site variability in viable seed production. A greater proportion of seeds germinated for $\mathrm{H}$. pilosella, with similarly high levels of variation in the proportion of seed germinating from different sites, but with no obvious relationship with age of seeds $\left(\mathrm{F}_{3,27}=13.100, P<0.0001\right.$, Fig. 3). Seeds of $H$. aurantiacum began germinating after 5 days reaching a maximum after a month, while seeds of $H$. pilosella began germinating after about 2 weeks and reached maximum after 5 weeks.

Seedling growth. For H. aurantiacum, no seedlings survived in the glasshouses at $200 \mathrm{~m}$ asl. These experienced some very warm days and all seedlings died. Seedlings at other temperatures produced on average $86.9 \pm 2.3$ leaves over the experimental period with no difference in seedlings grown at temperatures reflecting different altitudes $\left(1000 \mathrm{~m}\right.$ vs $1700 \mathrm{~m} ; \chi_{1}^{2}=1.796, P=0.180$; Fig. 4). However, seedlings at temperatures reflecting $1700 \mathrm{~m}$ were larger than those at $1000 \mathrm{~m}\left(\chi_{1}^{2}=19.020, P<0.001 ;\right.$ Fig. 5). The increase in dry weight was seen in the development of roots $\left(\chi_{1}^{2}=19.297, P<0.001\right.$; Fig. 5) rather than above ground biomass $\left(\chi_{1}^{2}=2.115\right.$, $P=0.146$; Fig. 5). Hieracium aurantiacum began producing stolons after 27 days from plantings at temperatures mimicking $1000 \mathrm{~m}$ but only after 40 days at when temperatures mimicked $1700 \mathrm{~m}$ although the proportion of dry weight as ramets $\left(\chi_{1}^{2}=2.906, P=0.088\right.$; Fig. 5) and average number of stolons at the end of the experiment $\left(\bar{x}=6.8 \pm 0.2, \chi^{2}=1.067, P=0.302\right.$; Fig. 6$)$ did not differ with temperature. Root:shoot ratios did not differ between the two temperature regimes (OHW $\bar{x}=2.4 \pm 0.1, \chi^{2}=1.000, P=0.317$ ).

Seedlings of $H$. aurantiacum had more leaves $(\bar{x}=88.9 \pm 3.1)$ than $H$. pilosella seedlings $(\bar{x}=75.2 \pm 4.3)$ at $1700 \mathrm{~m}\left(\chi_{1}{ }^{2}=22.916, P<0.001\right.$; Fig. $\left.4 \mathrm{~b}\right)$ and were significantly heavier $\left(\chi_{1}{ }^{2}=23.576, P<0.001\right.$; Fig. 5). This was due to an increase in roots $\left(\chi_{1}^{2}=18.976, P<0.001\right.$; Fig. 5) but not above ground biomass $\left(\chi_{1}^{2}=0.067, P=0.795\right.$; Fig. 5). Root:shoot ratios confirmed this change in resource allocation (MEHW $\bar{x}=1.6 \pm 0.1, \chi^{2}=5.254$, $P=0.022$ ). H. pilosella seedlings rarely produced stolons (and therefore ramets), averaging only $0.25 \pm 0.06$ stolons per plant (Fig. 6b). 


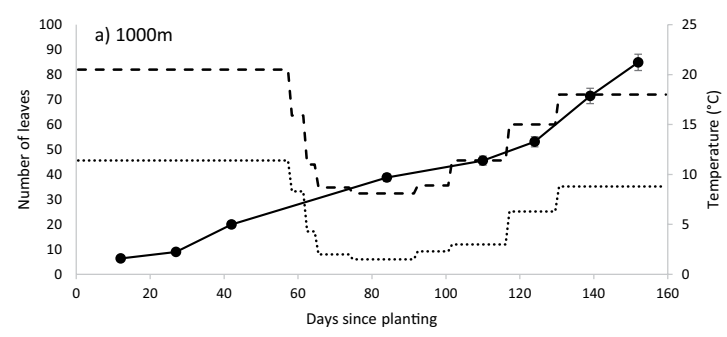

- - - day temperature …….. Night Temperature $\rightarrow$ Number of Leaves

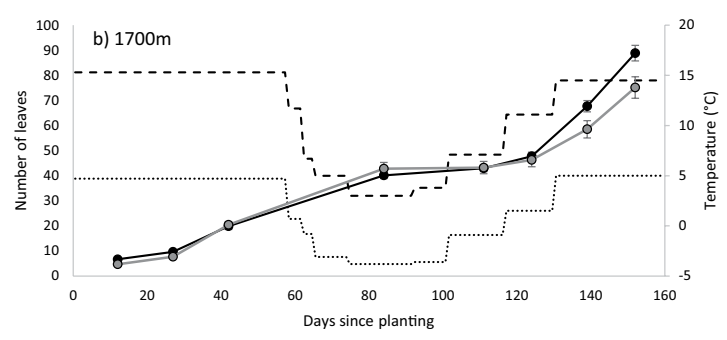

- - - Day Temperature ............ Night Temperature $\rightarrow$ OHW $\multimap$ МEHW

Figure 4. Average number of leaves ( \pm s.e.) of seedlings potted from germinants grown at conditions representative of (a) $1000 \mathrm{~m}$ and (b) $1700 \mathrm{~m}$ for H. auranticum (OHW) and H. pilosella (MEHW). There were no seedlings of $H$. pilosella at $1000 \mathrm{~m}$. Lines reflect the day (dashed) and night (dotted) temperatures in the cabinets through the experiment.

a) root and shoot dry biomass

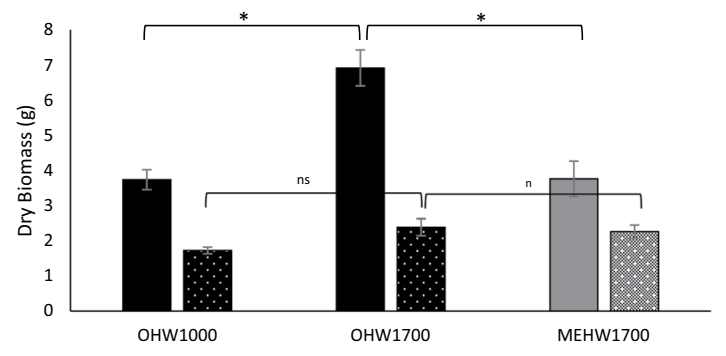

b) total dry biomass

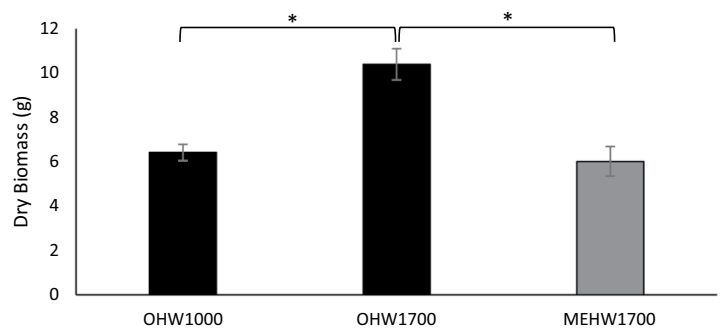

c) Proportion of dry biomass as ramets

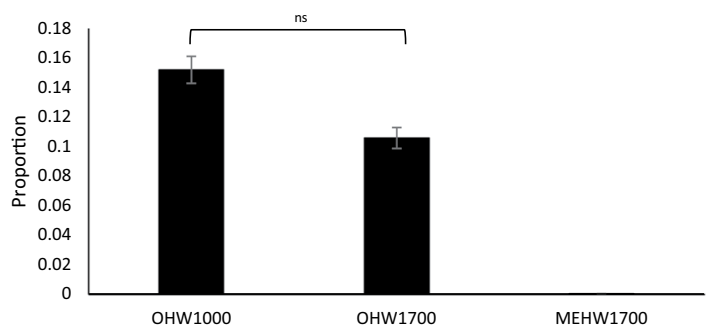

Figure 5. (a) Final average dry biomass per plant ( \pm s.e.) of roots (solid) and shoots (pitted), (b) average total dry biomass including ramet weights, (c) proportion of total dry biomass that is new ramets, of seedlings at final harvest for H. pilosella (MEHW) and H. aurantiacum (OHW) at temperatures reflecting two altitudes (1000 $\mathrm{m}$ and $1700 \mathrm{~m}$ asl). 

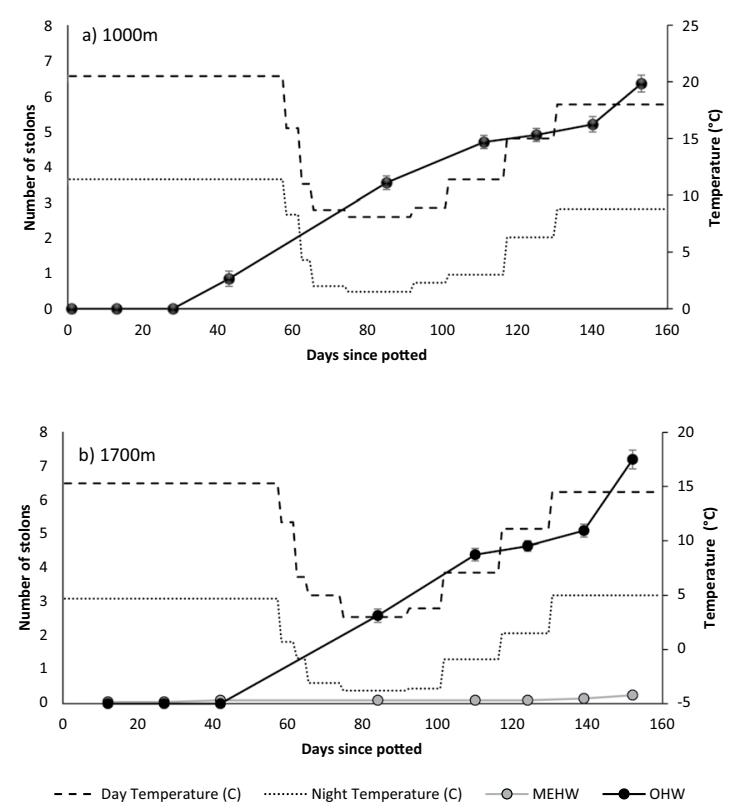

Figure 6. Average number of stolons ( \pm s.e.) grown from seedlings potted from germinants grown at conditions representative of (a) $1000 \mathrm{~m}$ and (b) $1700 \mathrm{~m}$ of H. aurantiacum (OHW)and H. pilosella (MEHW). There were no seedlings of $H$. pilosella at $1000 \mathrm{~m}$. Lines reflect the day (dashed) and night (dotted) temperatures in the cabinets through the experiment.
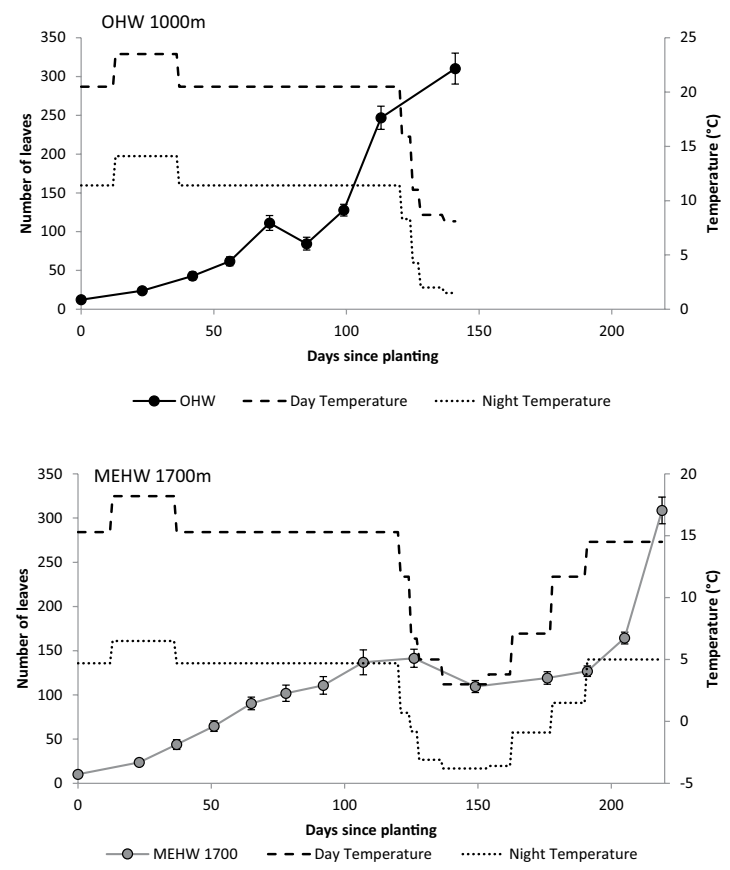

Figure 7. The number of leaves on established ramets through time of (a) H. aurantiacum (OHW) grown at conditions representative of $1000 \mathrm{~m}$ (b) H. pilosella (MEHW) grown at conditions representative of $1700 \mathrm{~m}$. H. aurantiacum plants were terminated early as plants had filled pots. Lines reflect the day (dashed) and night (dotted) temperatures in the cabinets through the experiment.

Plantlet growth. For the older plantlets, both species produced about 300 leaves per plantlet, but the time taken for this varied dramatically. Ramets of $H$. aurantiacum began with an average of $12.3 \pm 9.1$ (s.d.) leaves (range 5-29) and those of MEHW began with 10.3 \pm 6.2(s.d.) leaves (range 4-28). For H. aurantiacum, plantlets grew approximately 300 leaves over the late summer and autumn period (2.1 leaves per day), while $H$. pilosella plantlets didn't grow this many leaves until the following spring (overall 1.4 leaves per day; Fig. 7). Furthermore $H$. aurantiacum added an average of nearly 50 stolons per plant by the beginning of winter while $H$. pilosella had 

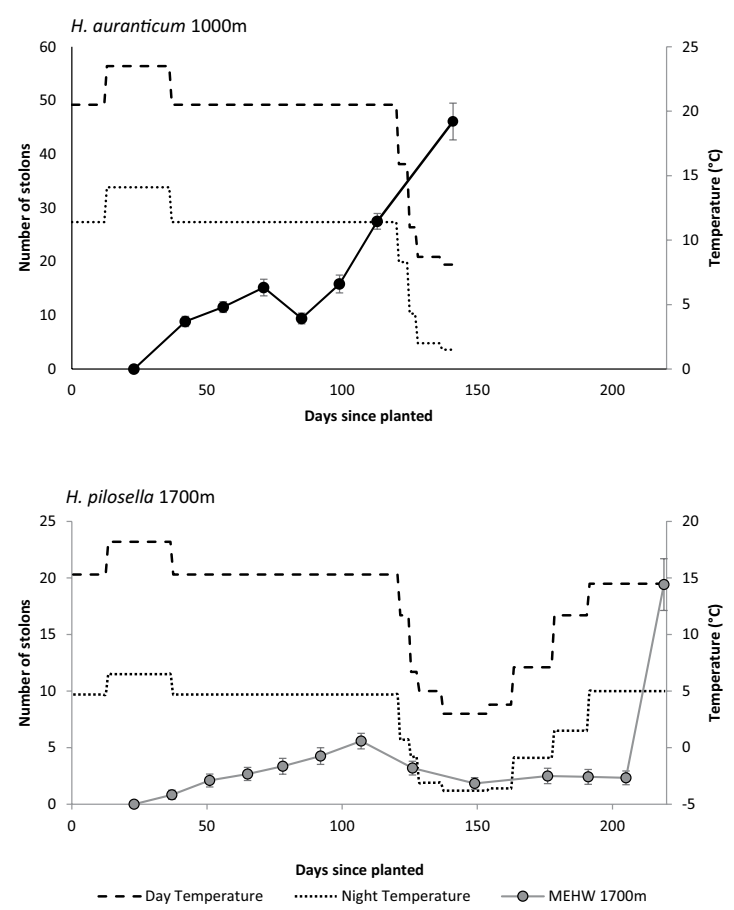

Figure 8. The number of stolons on established ramets through time of (a) H. aurantiacum (OHW) grown at conditions representative of $1000 \mathrm{~m}$ (b) H. pilosella (MEHW) grown at conditions representative of $1700 \mathrm{~m}$. OHW plants were terminated early as plants had filled pots. Lines reflect the day (dashed) and night (dotted) temperatures in the cabinets through the experiment.

a slower and lower production of ramets; in early spring $H$. pilosella plantlets had produced nearly 20 stolons per plant (Fig. 8). H. aurantiacum stolons were $21.4 \pm 10.9$ (s.d) \% of the total dry biomass yielding an overall allocation to vegetative reproduction of $25.7 \pm 11.7$ (s.d) \% of the total biomass (stolons plus ramets). Plants of both species started producing new stolons after about 40 days. For both species dry root biomass was at least double that of the biomass of both leaves and stolons (Fig. 9). The proportion of weight produced as ramets was only greater than $10 \%$ for H. aurantiacum (Fig. 9).

\section{Discussion}

Orange and mouse-ear hawkweed grew very quickly under the conditions provided in this experiment. Both species put considerably more into below-ground growth relative to above ground, even when ramet production was included. Below-ground capacity is very important in resource-poor habitats ${ }^{22-24}$ and strong below ground growth may increase resilience during snow covered winter periods, although no losses in leaves occurred at below freezing temperatures. Both species are likely to rely heavily, in the field, on the development of below ground biomass to aid competition and survival. Weigelt et al. ${ }^{25}$ found that competition occurred largely below ground in $H$. pilosella although it was less competitive under water limitation.

Invasive species are considered to be advantaged by developing strong growth in invaded ranges ${ }^{16,17}$ although field measurements are rare ${ }^{26,27}$. Invading plants would be expected to develop improved competitive attributes $\left(\right.$ EICA hypothesis ${ }^{28}$ ), however invaded range features may influence this. Rates were much quicker in our experiments than those measured in the field, perhaps associated with the well watered and non competitive conditions in this experiment. Thus, they more closely represent intrinsic growth rates. In the field in New Zealand, root:shoot ratios for $\mathrm{H}$. pilosella ${ }^{29}$ and overall growth rates were much lower ${ }^{25}$, suggesting competition is an important modifier. Certainly $H$. pilsosella tended to colonise poor quality and degraded soils in New Zealand ${ }^{30}$ and in native regions ${ }^{31}$ which reflects the conditions in the invaded area in Australia. It is known to influence resource acquisition in native species ${ }^{2}$. Together with our results, this suggests that hawkweeds have the capacity for fast growth in the invaded range under conditions of higher nutrients and lower competition.

We found a large difference between the two species in the allocation of resources to vegetative reproduction which were only partially explained by the different altitudes in which the two species have invaded in Australia. H. aurantiacum put significantly more resources into ramets, allocating up to between $4-15 \%$ of biomass depending on age. Stolon production began when seedlings were around 4 weeks at termperatures mimicking $1000 \mathrm{~m}$ and at 6 weeks at $1700 \mathrm{~m}$ indicating a strong vegetative growth response and was a significant component of biomass. In contrast, $H$. pilosella seedlings did not produce stolons with ramets and plantlets only produced stolons when plants were over 1 year old and probably closer to two years old. The rate of production of stolons was slow (2.6 stolons per month), in contrast to 9.8 stolons per month for H. aurantiacum. However, rates of stolon production in $H$. pilosella was about twice that recorded further south in Victoria $\left(\sim 5.5\right.$ stolons per month $\left.{ }^{32}\right)$ and greater than field plantlets in New Zealand (1.6 stolons per plantelet $\left.{ }^{33,34}\right)$. In New Zealand mouse-ear and king 

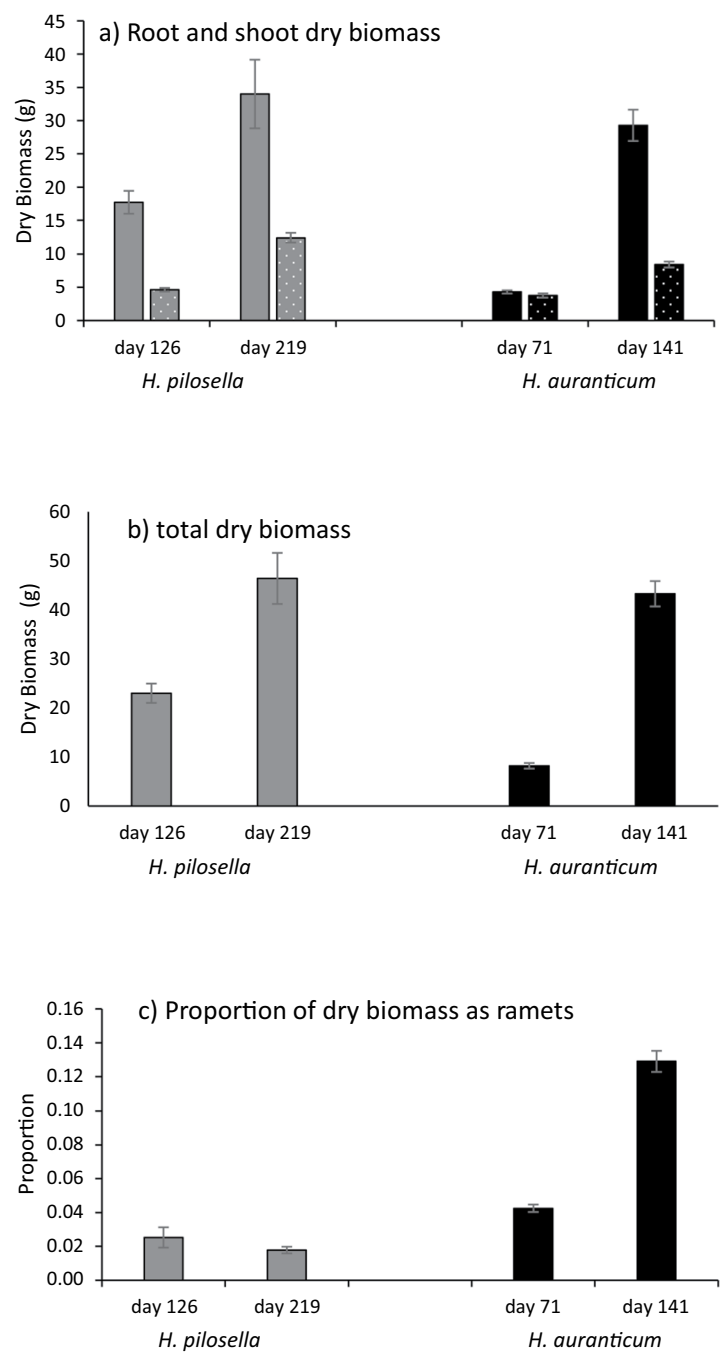

Figure 9. (a) Final average dry biomass per plant ( \pm s.e.) of roots (solid) and shoots (pitted), (b) average total dry biomass including ramet weights, (c) proportion of total dry biomass that is new ramets, of older ramets for $H$. pilosella and $H$. aurantiacum harvested at about halfway through experiment and at final harvest (days on y axis).

devil HW relied almost exclusively on clonal growth for population growth but clearly new incursions were a result of seed dispersal ${ }^{29}$. Relative to king devil HW, H. pilosella produced less seed, but more daughters which established further from the parent ${ }^{29}$. Our results suggest that $H$. aurantiacum is even more effective in spreading from vegetative growth. Furthermore, given that neither species produced flower spikes during our experiments, it suggests that $H$. aurantiacum was a more effective invader than mouse-ear in the NSW alps, spreading through stolons and the development of weed mats.

Both species were able to maintain strong growth, except when temperatures reflected winter norms, particularly at temperatures mimicking the higher altitude, when both species did not produce new leaves until temperatures came above zero. After the first five months of growth, seedlings had produced leaves at a rate of about 0.5 leaves day ${ }^{-1}$. Older plantlets grew more quickly; plantlets of $H$. aurantiacum producing 2.1 leaves day ${ }^{-1}$ from late summer - winter temperature settings where $H$. pilosella was 3 times slower $\left(0.7\right.$ leaves day $\left.{ }^{-1}\right)$ for the same period but it dramatically increased production when temperatures became wamer, and overall produced 1.4 leaves day ${ }^{-1}$. The increase in growth rate of established plants, suggests that, in order to achieve eradication, there is a window of opportunity of about 18 months prior to flowering and before a rapid increase in growth rate when invasion patches can be eradicated before creating significant breaks in native plant cover.

Hieracium pilosella had seeds with better germinability than $H$. aurantiacum, although neither were as high as measured by Bear et al. ${ }^{32}$ who found up to $89 \%$ germination for 3 month old, dry stored seeds. Better germination may be important if $H$. pilosella has greater allocation to reproduction rather than vegetative spread ${ }^{18}$. Hieracium pilosella benefits more from increased sexual reproduction in its invaded range than in native range ${ }^{18}$. Beckman et al..$^{18}$ only found $7 \%$ germination for $H$. pilosella in Germany. In NZ the high density of seed fall produced by $H$. pilosella, coupled with high seedling survival was thought to be important in the invasion of this species ${ }^{29,33}$. Seeds were equally viable with age, indicating a longer term seed bank may be able to develop. Further research on longevity in the field would be beneficial. 
Hieracium aurantiacum may well be able to germinate at lower altitudes but hot conditions experienced over the summer in these more coastal areas, may well limit the probablity of survival. About $10 \%$ of $\mathrm{H}$. aurantiacum seeds germinated at temperatures mimicking low altitudes, less than at lower temperatures mimicking higher altitudes, but seedlings did not survive the hot conditions experienced during the experiment. Despite this susceptibility, a cooler summer may allow establishment of seedlings and it is clear from this experiment that growth will be rapid. Once established, plants of both species appear to be resilient to hotter conditions. The hotter conditions experienced during the failure of the growth cabinets at day 146 (up to $24^{\circ} \mathrm{C}$ ) for $\mathrm{H}$. pilosella, and the very hot conditions $\left(>35^{\circ} \mathrm{C}\right)$ for $H$. aurantiacum at $1000 \mathrm{~m}$ had no visible effect on either species.

This study has shown the enormous capacity for growth of these two species of invading hawkweeds in the alpine regions in NSW, Australia. Vegetative reproduction is critical in the early stages of invasion to occupy space. $H$. aurantiacum was far more effective in vegetative growth compared to $H$. pilosella, suggesting its rate of spread will be much greater than $H$. pilosella. Both species, once established, appear to have significant mechanisms for tolerance derived from a large below ground biomass but also an apparent ability to easily cope with heat events when adequately watered. Further work is needed to understand hawkweed responses to interactions between temperature and other variations in climate that vary with altitude (rain/snowfall, wind etc). Understanding the negative effects of competition and nutrient limitation in the field in these species will greatly enhance our capacity to model spread in these species.

\section{Data availability}

Data are available at https://doi.org/10.5061/dryad.d2547d7zr.

Received: 23 August 2019; Accepted: 20 January 2020;

Published online: 07 February 2020

\section{References}

1. Vander Kloet, S. P. Biogeography of Hieracium pilosella L. In North America with special reference to Nova Scotia. Proc. N. S. Inst. Sci. 28, 127-34 (1978).

2. Diaz-Barradas, M. C. et al. Species-specific effects of the invasive Hieracium pilosella in Magellanic steppe grasslands are driven by nitrogen cycle changes. Plant Soil 397, 175-187 (2015).

3. Rauber, R. B., Cipriottim, P. A., Collantes, M. B., Martini, J. P. \& Frers, E. Regional suitability assessment for the mouseear hawkweed (Kieracium pilosella) invasion in Patagonian Rangelands. Inv. Plant Sci. Manage. 9, 242-251 (2016).

4. Bishop, G. F. \& Davy, A. J. Hieracium pilosella L. (Pilosella officinarum F. Schultz \& Schultz-Bip.). J. Ecol. 82, 195-210 (1994).

5. Rose, A. B., Platt, K. H. \& Frampton, C. M. Vegetation change over 25 years in a New Zealand short-tussock grassland: effects of sheep grazing and exotic invasions. N. Z. J. Ecol. 19, 163-174 (1995).

6. Hamilton, M. A., Cherry, H. \& Turner, P. J. Hawkweed eradication from NSW: Could this be 'the first'? Plant Protection Quarterly 30, 110-115(2015).

7. Beaumont, L. J. et al. Modelling the impact of Hieracium spp. on protected areas in Australia under future climates. Ecography 43, 757-764 (2009).

8. Harris, R. M. B., Kriticos, D. J., Remenyi, T. \& Bindoff, N. Unusual suspects in the usual places: a phylo-climatic framework to identify potential future invasive species. Biol. Invasions 19, 577-596 (2016).

9. Gadella, T. W. J. Sexual tetraploid and apomictic pentaploid populations of Hieracium pilosella, Compositae. Plant Syst. Evol. 157, 219-246 (1987).

10. Trewick, S. A., Morgan-Richards, M. \& Chapman, H. M. Chloroplast DNA diversity of Hieracium pilosella (Asteraceae) introduced to New Zealand: reticulation, hybridization, and invasion. American J. Bot. 91, 73-85 (2004).

11. Houliston, G. J., Chapman, H. M. \& Bicknell, R. A. The influence of genotype and environment on the fecundity and facultative expression of apomixis in Hieracium pilosella. Folia Geobotanica 41, 165-181 (2006).

12. Caraco, T. \& Kelly, C. K. On the adaptive value of physiological integration in clonal plants. Ecology 72, 81-93 (1991).

13. Batzer, E. E., Martina, J. P., Elgersma, K. J. \& Goldberg, D. E. Clonal plant allocation to daughter ramets is a simple function of parent size across species and nutrient levels. Plant Ecol. 218, 1299-1311, https://doi.org/10.1007/s11258-017-0769-z (2017).

14. Cadotte, M. W., Murray, B. R. \& Lovett-Doust, J. Ecological patterns and biological invasions: using regional species inventories in macroecology. Biol. Invasions 8, 809-821 (2006).

15. Liu, J. et al. Invasive alien plants in China: role of clonality and geographical origin. Biol. Invasions 8, 1461-1470 (2006).

16. Güsewell, S., Jakobs, G. \& Weber, E. Native and introduced populations of Solidago gigantea differ in shoot production but not in leaf traits or litter decomposition. Funct. Ecol. 20, 575-584 (2006).

17. Meyer, G. \& Hull-Sanders, H. Altered patterns of growth, physiology and reproduction in invasive genotypes of Solidago gigantea (Asteraceae). Biol. Invasions 3, 303-317 (2008).

18. Beckmann, M., Bruelheide, H. \& Erfmeier, A. Germination responses of three grassland species differ between native and invasive origins. Ecol. Res. 26, 763-771, https://doi.org/10.1007/s11284-011-0834-3 (2011).

19. Cipriotti, P. A., Rauber, R. B., Collantes, M. B., Braun, K. \& Escartin, C. Hieracium pilosella invasion in the Tierra del Fuego steppe, Southern Patagonia. Biol. Invasions 12, 523-2535 (2010).

20. Eriksson, O. Colonization dynamics and relative abundance of three plant species (Altennaria dioica, Hieracium pilosella and Hypochoeris maculata) in dry semi-natural grasslands. Ecography 20, 559-568 (1997).

21. Laube, J., Ziegler, K., Sparks, T. H., Estrella, N. \& Menzel, A. Tolerance of alien plant species to extreme events is comparable to that of their native relatives. Preslia 87, 31-53 (2015).

22. Berendse, F. Competition between plant populations with different rooting depths. III. Field experiments. Oecologia 53, 50-55 (1982).

23. Casper, B. B. \& Jackson, R. B. Plant competition underground. Annu. Rev. Ecol. Systematics 28, 545-570 (1997).

24. Coomes, D. A. \& Grubb, P. J. Impacts of root competition in forests and woodlands: A theoretical framework and review of experiments. Ecol. Monogr. 70, 171-207 (2000).

25. Weigelt, A., Steinlein, T. \& Beyschlag, W. Competition among three dune species: the impact of water availability on below-ground processes. Plant Ecol. 176, 57-68 (2005).

26. Bossdorf, O. et al. Phenotypic and genetic differentiation between native and introduced plant populations. Oecologia 144, 1-11 (2005).

27. Beckmann, M., Erfmeier, A. \& Bruelheide, H. A comparison of native and invasive populations of three clonal plant species in Germany and New Zealand. J. Biogeogr. 36, 865-878 (2009).

28. Blossey, B. \& Nötzold, R. Evolution of increased competitive ability in invasive nonindigenous plants: a hypothesis. J. Ecol. 83, 887-889 (1995) 
29. Makepeace, W. Growth, reproduction, and production biology of mouseear and king devil hawkweed in eastern South Island, New Zealand. N.Z. J. Bot. 23, 65-78 (1985).

30. Johnstone, P. D., Wilson, J. B. \& Bremner, A. G. Change in Hieracium populations in Eastern Otago over the period 1982-1992. New Zealand. J. Ecol. 23, 31-38 (1999).

31. Bartelheimer, M., Steinlein, T. \& Beyschlag, W. Aggregative root placement: A feature during interspecific competition in inland sand-dune habitats. Plant Soil 280, 101-114 (2006).

32. Bear, J. L., Giljohann, K. M., Cousens, R. D. \& Williams, N. S. G. The seed ecology of two invasive Hieracium (Asteraceae) species. Aust. J. Bot. 60, 615-624 (2012).

33. Day, N. U. J. \& Buckley, H. L. Invasion patterns across multiple scales by Hieracium species over 25 years in tussock grasslands of New Zealand's South Island. Austral Ecol. 36, 559-570 (2011).

34. Lamoureaux, S. L., Kelly, D. \& Barlow, N. D. Population dynamics in mature stands of Hieracium pilosella in New Zealand S.L. Plant Ecol. 166, 263-273 (2003).

\section{Acknowledgements}

This work was funded by a UOW partnership grant between the University of Wollongong and the NSW Office of Environment and Heritage. Thanks to Stephen Johnson and Pete Turner at the NSW Department of Primary Industries, Hillary Cherry and Mark Hamilton at NSW Office of Environment and Heritage for help in obtaining seeds and established plants and developing and discussing the study. Thanks also to Georgia Watson, Julia Rayment and Shae Jones for helping with the experiments.

\section{Author contributions}

K.F. designed the study, analysed the data and wrote the paper. E.W. managed the experiments, collected the data and undertook initial analysis. E.W. read and approved all drafts of the paper and final submission.

\section{Competing interests}

The authors declare no competing interests.

\section{Additional information}

Correspondence and requests for materials should be addressed to K.F.

Reprints and permissions information is available at www.nature.com/reprints.

Publisher's note Springer Nature remains neutral with regard to jurisdictional claims in published maps and institutional affiliations.

(c) (i) Open Access This article is licensed under a Creative Commons Attribution 4.0 International License, which permits use, sharing, adaptation, distribution and reproduction in any medium or format, as long as you give appropriate credit to the original author(s) and the source, provide a link to the Creative Commons license, and indicate if changes were made. The images or other third party material in this article are included in the article's Creative Commons license, unless indicated otherwise in a credit line to the material. If material is not included in the article's Creative Commons license and your intended use is not permitted by statutory regulation or exceeds the permitted use, you will need to obtain permission directly from the copyright holder. To view a copy of this license, visit http://creativecommons.org/licenses/by/4.0/.

(C) The Author(s) 2020 